\title{
NK-Cell Lymphoma, Unclassifiable
}

National Cancer Institute

\section{Source}

National Cancer Institute. NK-Cell Lymphoma, Unclassifiable. NCI Thesaurus. Code C128697.

A very rare NK-cell lymphoma with pathologic and clinical features posing difficulty in its exact diagnosis and classification. 